\title{
Dietary intake of phosphorus flame retardants (PFRs) using Swedish food market basket estimations
}

\author{
Giulia Poma a, *, Anders Glynn ${ }^{\text {b }}$, Govindan Malarvannan a , Adrian Covaci ${ }^{\text {a, **, }}$ \\ Per Ola Darnerud ${ }^{\mathrm{b}, * * *}$ \\ a Toxicological Center, University of Antwerp, Universiteitsplein 1, B-2610 Wilrijk, Belgium \\ ${ }^{\mathrm{b}}$ National Food Agency, P.O. Box 622, SE-75126 Uppsala, Sweden
}

\section{A R T I C L E I N F O}

Article history:

Received 7 November 2016

Received in revised form

8 December 2016

Accepted 10 December 2016

Available online 11 December 2016

\section{Keywords:}

Phosphorus flame retardants

Food

Market basket

per capita intake

Human exposure

\begin{abstract}
A B S T R A C T
The occurrence of eight phosphorus flame retardants (PFRs) was investigated in 53 composite food samples from 12 food categories, collected in 2015 for a Swedish food market basket study. 2-ethylhexyl diphenyl phosphate (EHDPHP), detected in most food categories, had the highest median concentrations (9 ng/g ww, pastries). It was followed by triphenyl phosphate (TPHP) (2.6 ng/g ww, fats/oils), tris(1,3(TCIPP) (0.80 ng/g ww, pastries). Tris(2-ethylhexyl) phosphate (TEHP), tri-n-butyl phosphate (TNBP), and tris(2-butoxyethyl) phosphate (TBOEP) were not detected in the analyzed food samples. The major contributor to the total dietary intake was EHDPHP (57\%), and the food categories which contributed the most to the total intake of PFRs were processed food, such as cereals (26\%), pastries (10\%), sugar/sweets (11\%), and beverages (17\%). The daily per capita intake of PFRs (TCEP, TPHP, EHDPHP, TDCIPP, TCIPP) from food ranged from 406 to $3266 \mathrm{ng} /$ day (or 6-49 ng/ $\mathrm{kg}$ bw/day), lower than the health-based reference doses. This is the first study reporting PFR intakes from other food categories than fish (here accounting for 3\%). Our results suggest that the estimated human dietary exposure to PFRs may be equally important to the ingestion of dust.
\end{abstract}

(c) 2016 Elsevier Ltd. All rights reserved.

\section{Introduction}

Because of the gradual restriction in use and phasing out of some brominated flame retardants (BFRs), such as polybrominated diphenyl ethers (PBDEs) and hexabromocyclododecane (HBCD), there is an urgent demand for alternative flame retardants (Wei et al., 2015). Due to their technical characteristics, phosphorus flame retardants (PFRs) are suitable alternatives for BFRs and are gaining an increasing interest, although they have been extensively used worldwide for several decades in a wide variety of consumer products (Wei et al., 2015; Van der Veen and De Boer, 2012). These chemicals are mostly used as flame retardants, plasticizers, and anti-foaming agents in industries, including plastics, furniture, textile, electronics, construction, vehicle, and petroleum industries (Marklund et al., 2003). In these applications, PFRs are additively

\footnotetext{
* Corresponding author.

** Corresponding author.

*** Corresponding author

E-mail addresses: giulia.poma@uantwerpen.be (G. Poma),adrian.covaci@ uantwerpen.be (A. Covaci), PerOla.Darnerud@slv.se (P.O. Darnerud).
}

used in the structure of host materials, but are not chemically bound to the product and thus they can reach the environment as a result of volatilization, leaching, and/or abrasion processes (Campone et al., 2010). Consequently, PFRs have already been detected worldwide in various environmental compartments, including sediments and soils (Zeng et al., 2014; Cao et al., 2012; Green et al., 2008), water (Rodil et al., 2012; Bollmann et al., 2012; Martínez-Carballo et al., 2007), air (Yang et al., 2014; Bi et al., 2010; Makinen et al., 2009; Green et al., 2008), indoor dust (Araki et al., 2014; Ali et al., 2013; Kim et al., 2013; Dodson et al., 2012; Stapleton et al., 2009), fish and biota (Brandsma et al., 2015; Malarvannan et al., 2015; Wang et al., 2014; Ma et al., 2013; Chen et al., 2012; Kim et al., 2011; Sundkvist et al., 2010), and humans (Kim et al., 2014; Marklund et al., 2010).

Data on the environmental persistence and toxicity of PFRs are, however, still limited and only a few reports on adverse effects have been published (Wei et al., 2015). For instance, tris-2chloroisopropylphosphate (TCIPP), tris-1,3-dichloro-2propylphosphate (TDCIPP), tris-2-butoxyethylphosphate (TBOEP), and tris-(2-chloroethyl) phosphate (TCEP) are suspected to be carcinogenic (Bollmann et al., 2012; Van der Veen and De Boer, 
2012; Meyer and Bester, 2004; WHO, 2000, 1998). Another potential effect of PFRs is neurotoxicity, based on their similarities with organophosphate pesticides that exert many neurodevelopmental effects through mechanisms that are unrelated to acute toxicity via cholinesterase inhibition (Dishaw et al., 2011). In addition, TDCIPP has been associated with altered hormone levels and decreased semen quality in humans (Stapleton et al., 2009), while 2ethylhexyldiphenylphosphate (EHDPHP) is considered highly toxic to fish and aquatic plants and has potential to bioaccumulate (Malarvannan et al., 2015; Bolgar et al., 2008). Therefore, the ubiquitous occurrence of PFRs in the environment and biota may pose a threat to human health through diverse routes, including dermal contact, dust ingestion/inhalation, and dietary intake. Foodstuffs, in fact, could be contaminated by bioaccumulation of PRFs in food of animal origin and during the food treatment processes and packaging (Campone et al., 2010). However, information on the worldwide presence of PFRs in foodstuffs is still scarce.

In the present study, eight PFRs, namely triphenyl phosphate (TPHP), TDCIPP, TCIPP, TCEP, tris(2-ethylhexyl) phosphate (TEHP), tri-n-butyl phosphate (TNBP), TBOEP, and EHDPHP, were analyzed in 53 composite food samples, belonging to 12 different food categories (including cereals, pastries, meat, fish, dairy products (fluid and solid), eggs, fats/oils, vegetables, fruit, potatoes, sugar/sweets, and beverages), from a recent Swedish food market basket study (2015). Based on the analysis results, the human per capita exposure to PFRs from food was then estimated and discussed.

\section{Materials and methods}

\subsection{Sample collection}

The Swedish Board of Agriculture (SBA) produces regularly updated reports of per capita consumption data based on production and trade statistics, providing information on annual market availability of food categories and foodstuff. In the present study, data for the calendar year 2013 has been used as basis for food purchase and in the following calculations (SBA, 2013). A shopping list was made by selecting different food items for each food category, considering the food groups consumed on average more than $0.5 \mathrm{~kg}$ per person per year (i.e. $1.5 \mathrm{~g}$ per person per day). This list covers approximately $90 \%$ of the total annual consumption expressed in $\mathrm{kg} /$ person.

In the present study, all food items were purchased in Uppsala, in May-June 2015, from five major grocery chains, with different distribution channels, and each food basket consisted of about 250 food items. The nationally largest selling brand/product and the grocery chain's own brand (if present) were used as criteria for selecting the food items. At the day of purchase, the food items were kept cold and/or frozen during transport. From each purchased food basket, the food items were sorted in 12 main food categories (Table 1 ), and the dairy products were split in two subgroups (5A and $5 \mathrm{~B}$ ) for sample homogeneity reasons. From each food item, one percent (by weight) of the yearly per capita consumption was taken out for homogenate preparation and subsequent analysis (Fig. S1). For food items where wastage could be supposed, inedible parts such as bone, skin, etc. were removed prior to homogenization. The weighed amount of sample from every food item within a food group (e.g. meat/meat products) was subsequently mixed and carefully blended (by using a household mixer). From these food group homogenates, samples were taken for analyses of PFR compounds.

\subsection{Chemicals and materials}

Standards of TCEP, TDCIPP, TEHP, EHDPHP, TCIPP (mixture of 2 isomers), and TPHP were purchased from Chiron AS (Trondheim, Norway). Triamyl phosphate (TAP) (IS) was purchased from TCI Europe (Zwijndrecht, Belgium). Labeled internal standards, TPHPd15, TDCIPP-d15, TBOEP-d6, and TCEP-d12 (IS) were custom synthesized. Recovery standard (RS) chlorobiphenyl CB-207 was purchased from Dr. Ehrenstorfer Laboratories (Augsburg, Germany). Polypropylene syringes were purchased by Sigma-Aldrich (St. Louis, MO, USA). QuE Z-Sep sorbent powder and Florisil ${ }^{\circledR}$ cartridges (500 mg, $3 \mathrm{~mL}$ ) were purchased from Supelco (Bellefonte, PA, USA). All solvents were chromatography grade: $n$-hexane (n-Hex) was purchased from Acros Organics (Belgium); ethyl acetate (ETAC), dichloromethane (DCM), iso-octane, and acetonitrile (ACN) were purchased from Merck (Darmstadt, Germany). All chemicals were analytical reagent grade or equivalent analytical purity.

\subsection{Sample preparation and instrumental analysis}

The method used for the analysis of PFRs in the food samples was based on the method described previously by Xu et al. (2015) with minor modifications. For the analysis of target compounds, $0.50 \mathrm{~g}$ of dry sample (equivalent to $0.70-5.0 \mathrm{~g}$ of wet weight, depending on the food group) or $0.10 \mathrm{~g}$ of fats/oils was added into a $25 \mathrm{~mL}$ polypropylene syringe with frit and cap at the bottom. Each sample was spiked with $50 \mu \mathrm{L}$ of IS mixture (TAP, TPHP-d15, TDCIPP-d15, TBOEP-d6, and TCEP-d12) and added with $5 \mathrm{~mL}$ of

\section{Table 1}

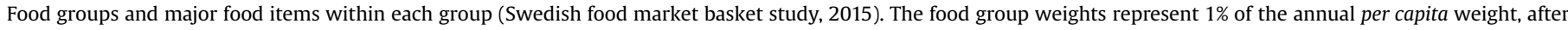
removal of inedible parts.

\begin{tabular}{|c|c|c|c|}
\hline Group & Food groups & Description of food items/categories & $\begin{array}{l}\text { Wt. of food group } \\
\text { homogenate }(\mathrm{g})\end{array}$ \\
\hline 1 & Cereal products & Flour, grain, corn flakes, pasta, bread & 836 \\
\hline 2 & Pastries & Biscuits, buns, cakes, pizza, pirogue & 177 \\
\hline 3 & Meat & Beef, pork, lamb, game, poultry, cured and processed meats (including meat products) & 774 \\
\hline 4 & Fish & Fresh and frozen, canned, shellfish (including fish products) & 167 \\
\hline $5 \mathrm{~A}$ & $\begin{array}{l}\text { Dairy products, } \\
\text { fluids }\end{array}$ & Milk, sour milk, yoghurt & 1180 \\
\hline $5 B$ & $\begin{array}{l}\text { Dairy products, } \\
\text { solids }\end{array}$ & Cheese (hard, processed, cottage), cream and sour cream & 290 \\
\hline 6 & Eggs & Fresh eggs & 101 \\
\hline 7 & Fats/oils & Butter, margarine, cooking oil, mayonnaise & 164 \\
\hline 8 & Vegetables & Fresh and frozen, incl. root vegetables, canned products & 721 \\
\hline 9 & Fruits & Fresh and frozen, canned products, juice, nuts, cordials, jam & 851 \\
\hline 10 & Potatoes & Fresh, French fries, potato crisps, potato purée (ready-made) & 461 \\
\hline 11 & Sugar/Sweets & $\begin{array}{l}\text { Sugar, honey, chocolate, sugar sweets, dairy and vegetable fat-based ice-cream, ready-made sauces and dressings, } \\
\text { mustard, ketchup, }\end{array}$ & 459 \\
\hline 12 & Beverages & Soft drinks, mineral water, beer (up to $3.5 \mathrm{vol} \%$ alcohol) & 1150 \\
\hline
\end{tabular}


ACN, vortexed $1 \mathrm{~min}$, and placed overnight at $+4{ }^{\circ} \mathrm{C}$. The following day, the sample was vortexed $1 \mathrm{~min}$ and the solvent was transferred in a pre-cleaned glass tube. The extract was concentrated to $2 \mathrm{~mL}$ and added with $160 \mathrm{mg}$ QuE Z-Sep sorbent powder. After performing the dispersive solid phase extraction (d-SPE), the extract was centrifuged and the supernatant was first transferred in a precleaned glass tube, concentrated to nearly dryness and finally reconstituted with $0.50 \mathrm{~mL}$ of $n$-Hex. The solution was then loaded on a Florisil ${ }^{\circledR}$ cartridge (pre-conditioned with $6 \mathrm{~mL}$ of ETAC and $6 \mathrm{~mL}$ of $n$-Hex). The fractionation was achieved with $12 \mathrm{~mL}$ of $n$ Hex:DCM $(1: 1 v / v)(\mathrm{F} 1)$ and $10 \mathrm{~mL}$ ETAC (F2). F1 (including analytical interferences, such as lipids and pigments) was discarded, while F2, containing the target analytes, was concentrated to nearly dryness and reconstituted with $50 \mu \mathrm{L}$ of RS (in isooctane:toluene, 9:1 $v / v)$ and $50 \mu \mathrm{L}$ of iso-octane:ETAC $(8: 2 v / v)$ solvent mixture. The sample was then transferred to injection vial and stored under $-20^{\circ} \mathrm{C}$ for at least $30 \mathrm{~min}$ before analysis on GC$\mathrm{EI} / \mathrm{MS}$ to precipitate residual lipids (if present, only the clear top layer was transferred to a new injection vial and injected).

PFRs were analyzed using an Agilent 6890 GC coupled to an Agilent 5973 MS operated in electron-impact (EI) mode. The GC system was equipped with a HT-8 column $(25 \mathrm{~m} \times 0.22 \mathrm{~mm}$, $0.25 \mu \mathrm{m})$, electronic pressure control and a programmabletemperature vaporizer (PTV) inlet. The injection temperature was set at $80{ }^{\circ} \mathrm{C}$, held $0.03 \mathrm{~min}$, ramped at $700{ }^{\circ} \mathrm{C} / \mathrm{min}$ to $300{ }^{\circ} \mathrm{C}$, held $40 \mathrm{~min}$. Injection $(1 \mathrm{~mL})$ was performed under a pressure of 13.65 psi until $1.25 \mathrm{~min}$ and purge flow to split vent of $50 \mathrm{~mL} / \mathrm{min}$ after $1.25 \mathrm{~min}$. The GC temperature ramp started from $80{ }^{\circ} \mathrm{C}$, held $1.25 \mathrm{~min}$, ramped at $15^{\circ} \mathrm{C} / \mathrm{min}$ to $200{ }^{\circ} \mathrm{C}$, held $3 \mathrm{~min}$, ramped at $5{ }^{\circ} \mathrm{C} /$ min to $270{ }^{\circ} \mathrm{C}$, ramped at $20^{\circ} \mathrm{C} / \mathrm{min}$ to $310^{\circ} \mathrm{C}$, held $12 \mathrm{~min}$. Helium was used as a carrier gas with a flow rate of $1.0 \mathrm{~mL} / \mathrm{min}$ until $28 \mathrm{~min}$, then increased to $1.5 \mathrm{~mL} / \mathrm{min}$. The mass spectrometer was run in SIM mode with 2 or 3 characteristic ions acquired for each analyte and the corresponding IS. TEHP, TCEP, TCIPP (2 isomers), EHDPHP, TPHP, TDCIPP, TNBP, and TBOEP were analyzed. TAP was used as IS for TEHP, TNBP; TCEP-d12 was used for TCEP and TCIPP (2 isomers); TBOEP-d6 was used for TBOEP; TPHP-d15 was used for TPHP and EHDPHP; TDCIPP-d15 was used for TDCIPP.

\section{4. $Q A / Q C$}

The quality assurance and control check was performed using the menhaden fish oil used in the first worldwide interlaboratory study (ILS) on PFRs (Brandsma et al., 2013). The measured values were within the range of the reference concentration $( \pm 15 \%)$, while the mean recoveries of the spiked IS standards ranged between 53 and $71 \%$, except for TBOEP-d6 (33\%). A procedural blank was analyzed every ten samples to check for laboratory contamination. The mean blank concentrations (Table S1) were subtracted from the values found in the samples. The limits of quantification (LOQs) were based on a signal noise ratio of 10 for compounds not present in the blanks or were calculated as three times of standard deviation of the blanks plus average blank values for compounds present in the blanks. Due to the different weights of the analyzed samples and to the various sensitivities of the analytes on the GC-EI/MS, LOQs differed per matrix and per compounds and ranged from 0.05 to $3 \mathrm{ng} / \mathrm{g}$ ww (Table S2).

\subsection{Estimation of per capita intake}

The per capita exposure concept derives from the Swedish Board of Agriculture data on food production and trade statistics (SBA, 2013). The calculation is based on the per capita consumption, which represents the calculated mean population consumption of various food groups derived from Swedish sales and production statistics. The per capita intake of the respective PFRs can then be derived by multiplying the per capita consumption amount of a specific food category by the concentration of the actual compound found in the food homogenate. Since this homogenate represent one percent of the whole annual consumption, the amount in the homogenate is multiplied by a factor 100 . This gives the yearly consumption of the actual compound, which subsequently could be expressed on a daily basis by dividing by 365 , as was earlier done e.g. in case of persistent organic pollutants in the 1999 Swedish food market basket study (Darnerud et al., 2006). To present the data also on a body weight basis, the average body weight of the Swedish population $(67.2 \mathrm{~kg})$, from estimations in the previous marked basket survey from 2010 (NFA, 2012), was used in the calculations. When calculating the mean and median concentrations of PFRs in food homogenates and the average per capita intakes, the non-detects were substituted with half the quantification levels $(<\mathrm{LOQ}=1 / 2 \mathrm{LOQ}$, i.e. medium bound, $\mathrm{MB})$.

\section{Results and discussion}

\subsection{Levels of PFRs}

The PFR concentrations measured in the different food groups, based on medium bound levels (MB), are presented in Table 2. Per each food group, the mean, median, and range of the PFRs measured in the food homogenates belonging to that specific food group were reported, while the total dataset of PFR concentrations is shown in Table S3. The percentage of non-detects varied between 55 and $100 \%$, depending on the compound. TEHP, TNBP, and TBOEP were not detected in any of the analyzed food samples and, therefore, they were not shown in the tables or included in the subsequent estimation of the per capita intake. The high percentage of non-detects could be due to a low accumulation/concentration of these compounds in biota and consequently in the human food chain (Greaves and Letcher, 2016; Van der Veen and De Boer, 2012). This lower accumulation/concentration of PFRs, when compared to e.g. PBDEs and PCBs, may be due to their rapid metabolism/excretion (Su et al., 2014). Although toxicokinetic information on PFRs is still limited, recent studies on the in vitro metabolism of PFRs (using rat, herring gull, and human liver microsomes) and on the analysis of PFR metabolites in human urine suggested that PFRs are likely metabolized and excreted rapidly and that the half-lives of the PFR parent compounds in blood, and of their metabolites in urine, are relatively short, on the order of several hours (Greaves et al., 2016; Meeker et al., 2013; Cooper and Stapleton, 2012).

Among the analyzed PFRs, EHDPHP had the highest median concentrations ( $9 \mathrm{ng} / \mathrm{g} \mathrm{ww}$ ) and was detected in most food groups, possibly due to the use of EHDPHP in food packaging materials (FDA, 2006). It was followed by TPHP ( $2.6 \mathrm{ng} / \mathrm{g} \mathrm{ww})$, TDCIPP (1.0 ng/ $\mathrm{g} w \mathrm{w})$, TCEP (1.0 ng/g ww), and TCIPP (0.80 ng/g ww). Literature data reporting PFR levels in biota and foodstuffs are still limited and mainly focused on fish (marine and freshwater species) and, to a lesser extent, on meat and egg contamination (Malarvannan et al., 2015; Xu et al., 2015). From a comparison with the existing data, the PFR levels measured in fish homogenates from our study (mean: $3.50 \mathrm{ng} / \mathrm{g}$ ww for the sum of considered PFRs) are in the same range as those observed in smoked salmon by Xu et al. (2015) (mean: $1.23 \mathrm{ng} / \mathrm{g} \mathrm{ww}$ ). Our data are lower than those measured in aquatic biota from Western Scheldt estuary, The Netherlands (median of 4.6 and $2.0 \mathrm{ng} / \mathrm{g}$ ww for TCIPP and TPHP, respectively) (Brandsma et al., 2015), in wild European eels from Belgian freshwater bodies (median of $8.4 \mathrm{ng} / \mathrm{g} \mathrm{ww}$ ) (Malarvannan et al., 2015), and in samples of fish and mussels from Swedish lakes and coastal areas (contamination pattern dominated by TCIPP, with levels between 170 and 770 ng/g lw) (Sundkvist et al., 2010). Also, the mean PFR 
Table 2

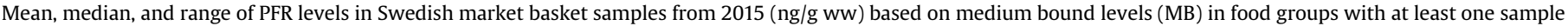
$>$ LOQ.

\begin{tabular}{|c|c|c|c|c|c|c|}
\hline Food groups & & TCEP & ТРHP & EHDPHP & TDCIPP & TCIPP $^{\mathrm{a}}$ \\
\hline \multirow[t]{3}{*}{ Cereals $(n=5)$} & mean & 0.25 & 0.34 & 4.17 & 0.38 & 1.23 \\
\hline & median & 0.25 & 0.25 & 4.24 & 0.25 & 0.59 \\
\hline & range & $<0.50$ & $<0.50-0.67$ & $<3.0-9.25$ & $<0.50-0.89$ & $0.40-2.80$ \\
\hline \multirow[t]{3}{*}{ Pastries $(n=2)$} & mean & 0.25 & 0.75 & 9.25 & 0.25 & 0.81 \\
\hline & median & 0.25 & 0.75 & 9.25 & 0.25 & 0.81 \\
\hline & range & $<0.50$ & $<0.50-1.240$ & $8.44-10.06$ & $<0.50$ & $0.70-0.91$ \\
\hline \multirow[t]{3}{*}{ Meat $(n=5)$} & mean & 0.10 & 0.46 & 0.64 & 0.18 & 0.08 \\
\hline & median & 0.10 & 0.23 & 0.50 & 0.10 & 0.08 \\
\hline & range & $<0.20$ & $<0.20-1.54$ & $<1.0-1.22$ & $<0.20-0.52$ & $<0.15$ \\
\hline \multirow[t]{3}{*}{ Fish $(n=5)$} & mean & 0.10 & 0.63 & 2.46 & 0.29 & 0.08 \\
\hline & median & 0.10 & 0.43 & 1.75 & 0.10 & 0.08 \\
\hline & range & $<0.2$ & $<0.20-1.56$ & $<1.0-5.80$ & $<0.20-1.05$ & $<0.15$ \\
\hline \multirow[t]{3}{*}{ Dairy, fluid $(n=4)$} & mean & 0.13 & 0.08 & 0.43 & 0.18 & 0.06 \\
\hline & median & 0.12 & 0.08 & 0.43 & 0.08 & 0.06 \\
\hline & range & $<0.10-0.22$ & $<0.10-<0.20$ & $<0.70-<1.0$ & $<0.10-0.50$ & $<0.10-<0.15$ \\
\hline \multirow[t]{3}{*}{ Dairy, solid $(n=5)$} & mean & 0.15 & 0.15 & 1.00 & 0.15 & 0.10 \\
\hline & median & 0.15 & 0.15 & 1.00 & 0.15 & 0.10 \\
\hline & range & $<0.3$ & $<0.3$ & $<2.0$ & $<0.30$ & $<0.20$ \\
\hline \multirow[t]{3}{*}{ Eggs $(n=5)$} & mean & 0.08 & 0.08 & 0.91 & 0.18 & 0.13 \\
\hline & median & 0.08 & 0.08 & 0.89 & 0.12 & 0.11 \\
\hline & range & $<0.15-<0.20$ & $<0.15-<0.20$ & $0.58-1.26$ & $<0.15-0.39$ & $<0.15-0.23$ \\
\hline \multirow[t]{3}{*}{ Fats/oils $(n=4)$} & mean & 1.00 & 4.74 & 5.08 & 1.00 & 0.75 \\
\hline & median & 1.00 & 2.62 & 4.85 & 1.00 & 0.75 \\
\hline & range & $<2.0$ & $1.36-12.37$ & $<6.0-7.61$ & $<2.0$ & $<1.5$ \\
\hline \multirow[t]{3}{*}{ Vegetables $(n=5)$} & mean & 0.41 & 0.07 & 0.28 & 0.37 & 0.18 \\
\hline & median & 0.45 & 0.06 & 0.29 & 0.21 & 0.17 \\
\hline & range & $0.32-0.51$ & $<0.05-0.13$ & $<0.2-0.39$ & $<0.05-1.06$ & $<0.05-0.33$ \\
\hline \multirow[t]{3}{*}{ Fruits $(n=5)$} & mean & 0.09 & 0.08 & 0.47 & 0.29 & 0.11 \\
\hline & median & 0.08 & 0.08 & 0.35 & 0.24 & 0.08 \\
\hline & range & $<0.15-0.16$ & $<0.15$ & $<0.7-0.95$ & $<0.15-0.57$ & $<0.15-0.24$ \\
\hline \multirow[t]{3}{*}{ Potatoes $(n=5)$} & mean & 0.11 & 0.18 & 0.35 & 0.29 & 0.17 \\
\hline & median & 0.08 & 0.08 & 0.35 & 0.29 & 0.18 \\
\hline & range & $<0.15-0.26$ & $<0.15-0.48$ & $<0.70$ & $0.18-0.49$ & $<0.15-0.29$ \\
\hline \multirow[t]{3}{*}{ Sugar/sweets $(n=2)$} & mean & 0.23 & 0.25 & 3.71 & 0.74 & 0.20 \\
\hline & median & 0.23 & 0.25 & 3.71 & 0.74 & 0.20 \\
\hline & range & $<0.45$ & $<0.50$ & $<3.0-5.92$ & $<0.5-1.23$ & $<0.40$ \\
\hline \multirow[t]{3}{*}{ Beverages $(n=2)$} & mean & 0.23 & 0.25 & 1.50 & 0.86 & 0.20 \\
\hline & median & 0.23 & 0.25 & 1.50 & 0.86 & 0.20 \\
\hline & range & $<0.45$ & $<0.50$ & $<3.0$ & $0.64-1.07$ & $<0.40$ \\
\hline
\end{tabular}

${ }^{\text {a }}$ Sum of two isomers.

levels measured in meat and eggs from the present study are similar to those observed in lean pork ( $0.30 \mathrm{ng} / \mathrm{g} \mathrm{ww}$ for EDHPHP) and free range eggs ( $0.27 \mathrm{ng} / \mathrm{g}$ ww for TPHP) analyzed by Xu et al. (2015).

Interestingly, the distribution of PFRs in the analyzed food categories shows that cereals, pastries, fats/oils, and sugar/sweets have the highest medium bound PFR contamination (Fig. 1). These food categories are more industrially processed, compared to the other food groups, possibly suggesting that their contamination arises during food processing. The lower contamination with PFRs in foods of animal origin, in addition, might be due to their rapid metabolism and excretion though urine (Greaves et al., 2016; Su et al., 2014; Meeker et al., 2013).

\subsection{Estimation of per capita intake of PFRs via diet}

The calculated per capita intakes of five PFRs from each food category and the total intake of PFRs considering all the food groups are reported in Table 3. For the average adult population, the calculated daily medium-bound per capita intakes of PFRs from food ranged from 406 to $3266 \mathrm{ng} /$ day and from 6 to $49 \mathrm{ng} / \mathrm{kg} \mathrm{bw} /$ day for the five different compounds. The major contributor to the total intake was in the order of EHDPHP (57\%) > TDCIPP $(14 \%)>\operatorname{TPHP}(11 \%)>\operatorname{TCIPP}(10 \%)>\operatorname{TCEP}(7 \%)$, whereas the food categories contributing most to the total PFR intake were cereals (26\%), followed by beverages (17\%), sugar/sweets (11\%) and pastries
(10\%). The specific contribution of all the analyzed food categories to the intake of the five PFRs is represented in Fig. S2.

In a Swedish study, based on the levels of the sum of eight PFRs in fish (with a consumption of $375 \mathrm{~g} /$ week), the resulting intake of PFRs was calculated as up to $20 \mathrm{ng} / \mathrm{kg}$ bw/day (Sundkvist et al., 2010). Malarvannan et al. (2015) determined the human intake of PFRs based on levels in Belgian eels, and the median intake of certain PFRs for high consumers (recreational fishermen and their families) were at most $1 \mathrm{ng} / \mathrm{kg}$ bw/day for TCIPP. Kim et al. (2013) determined the total dietary intake of seven PFRs (22 ng/kg bw/ day) in fish from Philippines. In an US market basket study (Gunderson, 1988), the PFR intake was calculated as $0.3-4.4 \mathrm{ng} /$ $\mathrm{kg}$ bw/day for TPHP. The calculated PFR intake from food in the present study are in the same order of magnitude of the previously cited studies, but these were only based on fish intake, whereas the intake estimations of the present Swedish food market basket were based on 12 food categories.

In addition, the estimated per capita dietary intake values of four of the PFR compounds analyzed in this study (TCEP, TCIPP, TPHP, and TDCIPP) were compared to the available reference doses (RfD) for the target PFRs, obtained by dividing the chronic no-observedadverse-effect-levels (NOAELs) by a safety factor of 1000 (Ali et al., 2012a). Daily intakes above 80,000 for TCIPP, 70,000 for TPHP, 15,000 for TDCIPP, and $22,000 \mathrm{ng} / \mathrm{kg}$ bw/day for TCEP are expected to cause health risks. Our calculated daily per capita intakes of these four PFRs from food (between 6 and $12 \mathrm{ng} / \mathrm{kg}$ bw/day, representing 

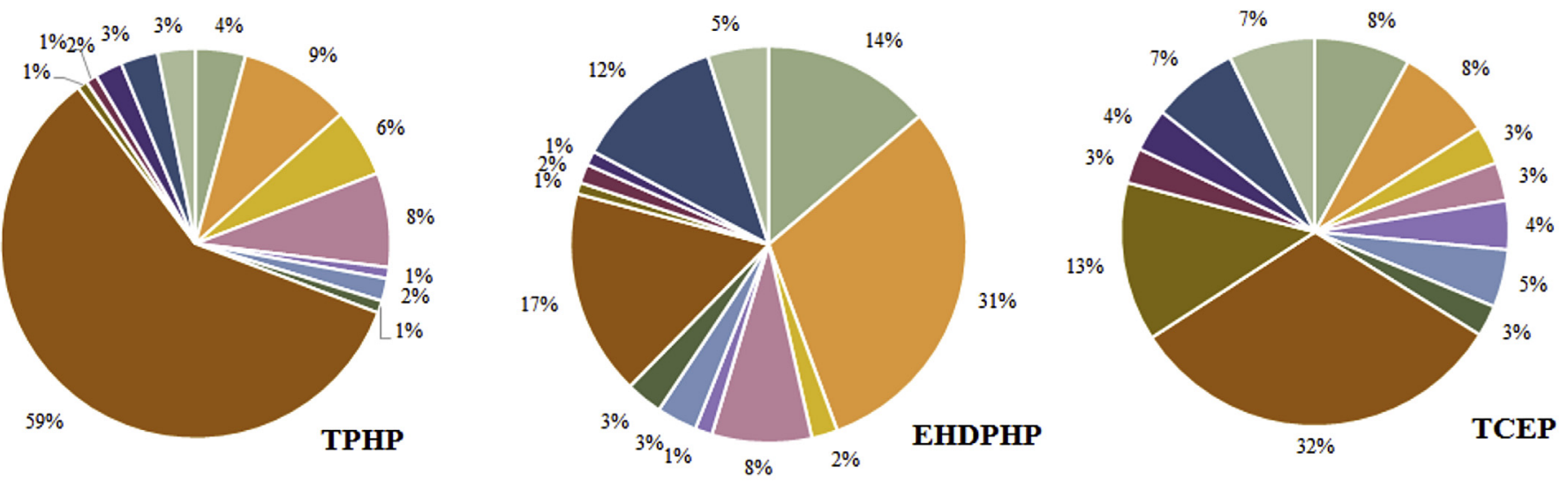

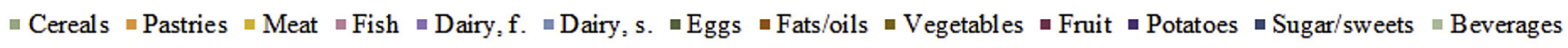
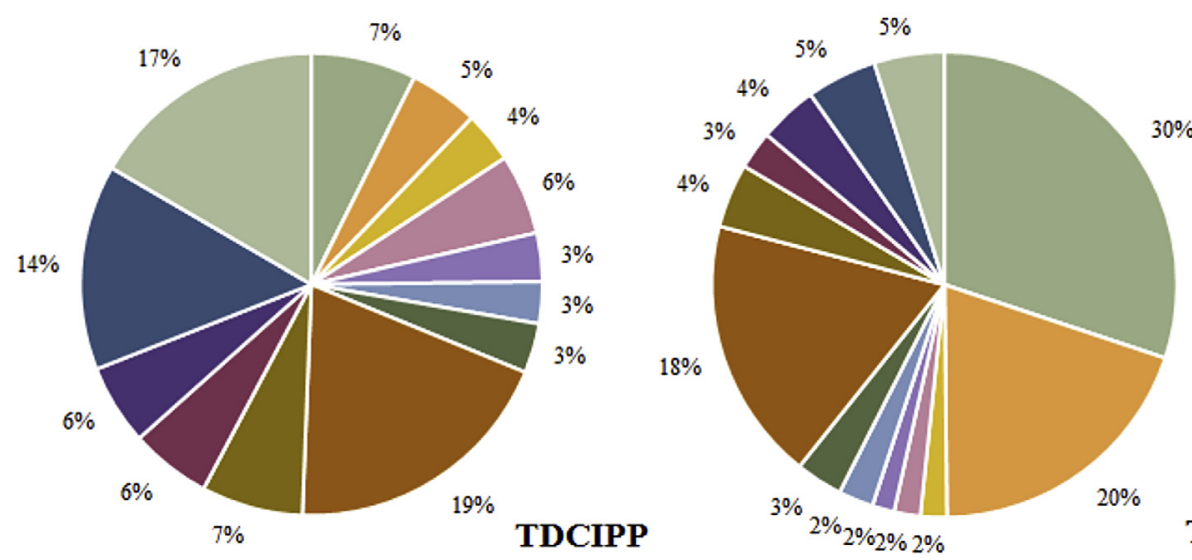

Fig. 1. Mean distribution of the five PFR levels in the analyzed food categories.

Table 3

Estimation of per capita intake of individual PFRs from each food category based on MB levels (ng/day) and total intake considering all the food groups (ng/day and ng/ $\mathrm{kg}$ bw/day). Reference dose (RfD) values ( $\mathrm{ng} / \mathrm{kg}$ bw/day) were calculated by dividing chronic NOAEL by a factor of 1000 (Ali et al., 2012a).

\begin{tabular}{llllll}
\hline & TCEP & TPHP & EHDPHP & TDCIPP & TCIPP $^{\text {a }}$ \\
\hline $\begin{array}{l}\text { RfD values (ng/kg bw/day) } \\
\text { food groups }\end{array}$ & 22,000 & 70,000 & - & 15,000 & 80,000 \\
Cereals & 57 & 77 & 955 & 87 & 282 \\
Pastries & 12 & 36 & 448 & 12 & 39 \\
Meat & 21 & 97 & 136 & 39 & 15 \\
Fish & 4 & 28 & 112 & 13 & 3 \\
Dairy, fluid & 41 & 24 & 137 & 56 & 20 \\
Dairy, solid & 11 & 11 & 79 & 11 & 7 \\
Eggs & 2 & 2 & 25 & 4 & 3 \\
Fats/oils & 44 & 213 & 228 & 44 & 33 \\
Vegetables & 81 & 13 & 55 & 72 & 36 \\
Fruits & 21 & 17 & 109 & 67 & 25 \\
Potatoes & 14 & 23 & 44 & 36 & 21 \\
Sugar/sweets & 28 & 31 & 466 & 92 & 25 \\
Beverages & 70 & 78 & 472 & 269 & 63 \\
\hline Total (ng/day) & 406 & 650 & 3266 & 802 & 572 \\
Total (ng/kg bw/day) & 6.0 & 9.7 & 48.6 & 11.9 & 8.5 \\
\hline \% of RfD & 0.03 & 0.01 & - & 0.08 & 0.01 \\
\hline a Sum of two isomers. & & & & & \\
b Using the per capita body & weight of $67.2 \mathrm{~kg}$. & & & \\
& & & & &
\end{tabular}

from 0.01 to $0.08 \%$ of the reported RfD) (Table 3 ) were several orders of magnitude lower than the indicated reference dose values.

\subsection{Considerations on exposure routes for PFRs in humans}

Because of the frequent occurrence of PFRs in the environment and their possible accumulation in biota samples, humans are exposed to PFRs via different exposure routes (Wei et al., 2015). One of the most important exposure pathways is ingestion (and inhalation) of dust (van de Eede et al., 2011; Sundkvist et al., 2010), to date considered more important than the food ingestion (Wei et al., 2015). The PFR concentrations in indoor dust are usually in the $\mu \mathrm{g} / \mathrm{g}$ range, which is 1000 -fold higher than the range of concentrations measured in foodstuffs ( $\mathrm{ng} / \mathrm{g}$ range). However, the average estimated ingestion rate of dust ( $20 \mathrm{mg} /$ day for adults) (Jones-Otazo et al., 2005) is 1000 to 100,000 -fold lower than food consumption, which is typically in the range of hundreds of g/day for adults.

The typical high-end ranges of PFR exposure via dust ingestion (Fig. 2) were estimated at $6.6 \mathrm{ng} / \mathrm{kg}$ bw/day for Belgian adults workers (Van de Eede et al., 2011), at $6.5 \mathrm{ng} / \mathrm{kg}$ bw/day for German adults (Brommer et al., 2012), at $3.0 \mathrm{ng} / \mathrm{kg}$ bw/day for adults in New Zealand (Ali et al., 2012a), at $9.7 \mathrm{ng} / \mathrm{kg}$ bw/day for adults in Stockholm (Luongo and Ostman, 2016), at $2.6 \mathrm{ng} / \mathrm{kg}$ bw/day for adults living in urban areas of Romania (Dirtu et al., 2012), at 0.45 and $6.35 \mathrm{ng} / \mathrm{kg}$ bw/day in adults from Pakistan and Kuwait, respectively (Ali et al., 2013), at $0.19 \mathrm{ng} / \mathrm{kg}$ bw/day for adults in Egypt (Abdallah and Covaci, 2014), and at $0.22 \mathrm{ng} / \mathrm{kg} \mathrm{bw} /$ day in adults from Philippines (Kim et al., 2013). In the present study, a wide range of food categories was included in the estimation of the human exposure to PFRs via diet. Thus, the estimated per capita intakes by adults of PFRs from food (total intake of $85 \mathrm{ng} / \mathrm{kg}$ bw/day for the 


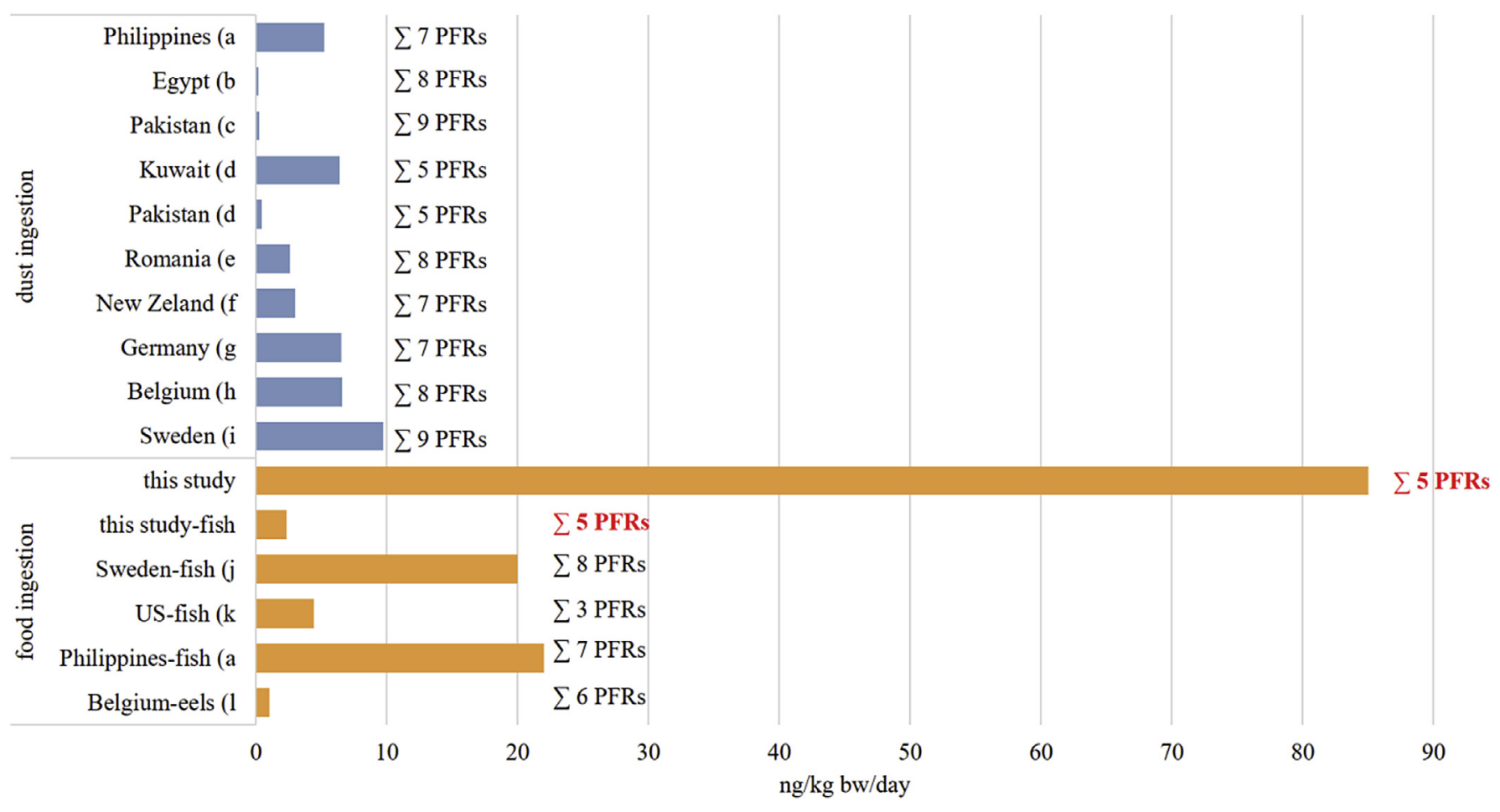

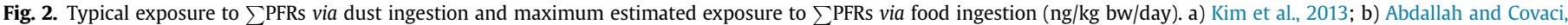

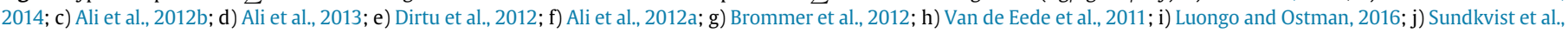
2010; k) Gunderson, 1988; l) Malarvannan et al., 2015. Please note that $\sum$ PFRs is composed of different PFRs in the mentioned studies.

sum of 5 PFRs) (Fig. 2) were generally higher than those estimated from dust, making the PFR exposure via diet equally or more important.

\subsection{Strengths and limitations of the study}

The present study provides new information about the human exposure to PFRs via food consumption, since very few papers have earlier reported, and all relevant food categories were included in the exposure estimation. However, many analytical results were below the assessed limits of quantification (which could affect the precision of the data), but enough QA/QC measures, including an appropriate number of laboratory blanks and tests on reference material, were performed to conclude that the analyses have been conducted in optimal conditions. To show how much data $<$ LOQ affected our results, the estimation of the per capita intake of PFRs was determined also on lower and upper bound basis (LB and UB), and the influence of the $\angle \mathrm{LOQ}$ values, expressed as the ratio UB/LB, was calculated (Table S4). In addition, no reference dose value (RfD) for EHDPHP is available in literature. Therefore, it was not possible to compare the estimated per capita dietary intake values of this compound obtained from this study with a reference value. Finally, due to the rapid metabolism and excretion of PFRs, the analysis of PFR parent compounds in foods of animal origin (such as meat or fish) could not reveal the actual accumulation in the animal body. For this reason, a further investigation on the PFR metabolites in food of animal origin will be of great interest.

\section{Conclusions}

In the present work, eight PFRs were analyzed in food composites from a Swedish market basket in 2015. Measurable PFR levels were found in several of the 12 studied food groups and the categories cereals, pastries, fats/oils, and sugar/sweets showed the highest levels of contamination. Based on the analysis results, the human per capita exposure to PFRs from food was estimated and found much lower than the health-based reference points. However, although lower levels of PFRs could be found in food than in dust, our results suggest that the PFR exposure via diet is equally important to the one via ingestion of indoor dust, as the food intake is comparably much higher.

\section{Acknowledgments}

The financial support was provided from the Swedish Environment Protection Agency. Dr. Poma and Dr. Malarvannan acknowledge postdoctoral fellowships from the University of Antwerp.

\section{Appendix A. Supplementary data}

Supplementary data related to this article can be found at http:// dx.doi.org/10.1016/j.fct.2016.12.011.

\section{Transparency document}

Transparency document related to this article can be found online at http://dx.doi.org/10.1016/j.fct.2016.12.011.

\section{References}

Abdallah, M.A. Covaci, A., 2014. Organophosphate flame retardants in indoor dust from Egypt: implications for human exposure. Environ. Sci. Technol. 48, 4782-4789.

Ali, N., Ali, L., Mehdi, T., Dirtu, A.C., Al-Shammari, F., Neels, H., Covaci, A., 2013. Levels and profiles of organochlorines and flame retardants in car and house dust from Kuwait and Pakistan: implication for human exposure via dust ingestion. Environ. Int. 55, 62-70.

Ali, N., Dirtu, A.C., Van den Eede, N., Goosey, E., Harrad, S., Neels, H., t Mannetje, A.t. Coakley, J., Douwes, J., Covaci, A., 2012a. Occurrence of alternative flame retardants in indoor dust from New Zealand indoor sources and human exposure assessment. Chemosphere 88, 1276-1282. 
Ali, N., Van den Eede, N., Dirtu, A.C., Neels, H., Covaci, A., 2012b. Assessment of human exposure to indoor organic contaminants via dust ingestion in Pakistan. Indoor Air 22, 200-211.

Araki, A., Saito, I., Kanazawa, A., Morimoto, K., Nakayama, K., Shibata, E., Tanaka, M., Takigawa, T., Yoshimura, T., Chikara, H., Saijo, Y., Kishi, R., 2014. Phosphorus flame retardants in indoor dust and their relation to asthma and allergies of inhabitants. Indoor Air 24, 3-15.

Bi, X.H., Simoneit, B.R.T., Wang, Z.Z., Wang, X.M., Sheng, G.Y., Fu, J.M., 2010. The major components of particles emitted during recycling of waste printed circuit boards in a typical e-waste workshop of South China. Atmos. Environ. 44 4440-4445.

Bolgar, M., Hubball, J., Groeger, J., Meronek, S., 2008. Handbook for the Chemical Analysis of Plastic and Polymer Additives. CRC Press Taylor\&Francis Group, NewYork.

Bollmann, U.E., Moeler, A., Xie, Z.Y., Ebinghaus, R., Einax, J.W., 2012. Occurrence and fate of organophosphorus flame retardants and plasticizers in coastal and marine surface waters. Water Res. 46, 531-538.

Brandsma, S.H., de Boer, J., Cofino, W.P., Covaci, A., Leonards, P.E.G., 2013. Organophosphorus flame-retardant and plasticizer analysis, including recommendations from the first worldwide interlaboratory study. TRAC Trends Anal. Chem. 43, 217-228.

Brandsma, S.H., Leonards, P.E., Leslie, H.A., de Boer, J., 2015. Tracing organophosphorus and brominated flame retardants and plasticizers in an estuarine food web. Sci. Total Environ. 505, 22-31.

Brommer, S., Harrad, S., Van den Eede, N., Covaci, A., 2012. Concentrations of organophosphate esters and brominated flame retardants in German indoor dust samples. J. Environ. Monit. 14, 2482-2487.

Campone, L., Piccinelli, A.L., Östman, C., Rastrelli, L., 2010. Determination of organophosphorus flame retardants in fish tissues by matrix solid-phase dispersion and gas chromatography. Anal. Bioanal. Chem. 397, 799-806.

Cao, S.X., Zeng, X.Y., Song, H., Li, H.R., Yu, Z.Q., Sheng, G.Y., Fu, J.M., 2012. Levels and distributions of organophosphate flame retardants and plasticizers in sediment from Taihu Lake, China. Environ. Toxicol. Chem. 31, 1478-1484.

Chen, D., Letcher, R.J., Chu, S., 2012. Determination of non-halogenated, chlorinated and brominated organophosphate flame retardants in herring gull eggs based on liquid chromatography etand emquadrupole mass spectrometry. J. Chromatogr. A 1220, 169-174.

Cooper, E.M., Stapleton, H.M., 2012, Metabolism of organophosphate flame retardants by human liver microsomes and porcine esterase, Proceedings of the Society of Environmental Toxicology and Chemistry (SETAC) North America 32nd Annual Meeting, November 13-17, 2011. http://boston.setac.org/sites default/files/abstract-book-2011_web_0.pdf.

Darnerud, P.O., Atuma, S., Aune, M., Bjerselius, R., Glynn, A., Grawe, K.P., Becker, W. 2006. Dietary intake estimations of organohalogen contaminants (dioxins, PCB, PBDE and chlorinated pesticides, e.g. DDT) based on Swedish market basket data. Food Chem. Toxicol. 44, 1597-1606.

Dirtu, A.C., Ali, N., Van den Eede, N., Neels, H., Covaci, A., 2012. Country specific comparison for profile of chlorinated, brominated and phosphate organic contaminants in indoor dust. Case study for Eastern Romania, 2010. Environ. Int. $49,1-8$.

Dishaw, L.V., Powers, C.M., Ryde, I.T., Roberts, S.C., Seidler, F.J., Slotkin, T.A Stapleton, H.M., 2011. Is the PentaBDE replacement, tris (1,3-dichloropropyl) phosphate (TDCIPP), a developmental neurotoxicant? Studies in PC12 cells Toxicol. Appl. Pharmacol. 256, 281-289.

Dodson, R.E., Perovich, L.J., Covaci, A., Ionas, A.C., Dirtu, A.C., Brody, J.G., Rudel, R.A., 2012. After the PBDE phase-out: a broad suite of flame retardants in repeat house dust Samples from California. Environ. Sci. Technol. 46, 13056-13066.

FDA (US Food and Drug Administration), 2006. Food Additive Status List. http:/ www.fda.gov/Food/IngredientsPackagingLabeling/PackagingFCS/default.htm.

Greaves, A.K., Letcher, R.J., 2016. A review of organophosphate esters in the environment from biological effects to distribution and fate. Bull. Environ. Contam. Toxicol. http://dx.doi.org/10.1007/s00128-016-1898-0.

Greaves, A.K., Su, G., Letcher, R.J., 2016. Environmentally relevant organophosphate triester flame retardants in herring gulls: in vitro biotransformation and kinetics and diester metabolite formation using a hepatic microsomal assay. Toxicol. Appl. Pharmacol. 308, 59-65.

Green, N., Schlabach, M., Bakke, T., Brevik, E.M., Dye, C., Herzke, D., Huber, S. Plosz, B., Remberger, M., Schoyen, M., Uggerud, H.T., Vogelsang, C., 2008 Screening of Selected Metals and New Organic Contaminants 2007. Norwegian Pollution Control Agency.

Gunderson, E.L., 1988. FDA total diet study, April 1982-April 1984, dietary intakes of pesticides, selected elements, and other chemicals. J. Assoc. Off. Anal. Chem. 71 1200-1209.

Jones-Otazo, H.A., Clarke, J.P., Diamond, M.L., Archbold, J.A., Ferguson, G., Harner, T. Richardson, G.M., Ryan, J.J., Wilford, B., 2005. Is house dust the missing exposure pathway for PBDEs? An analysis of the urban fate and human exposure to PBDEs. Environ. Sci. Technol. 39, 5121, 1530.

Kim, J.W., Isobe, T., Chang, K.-H., Amano, A., Maneja, R.H., Zamora, P.B., Siringan, F.P., Tanabe, S., 2011. Levels and distribution of organophosphorus flame retardants and plasticizers in fishes from Manila Bay, the Philippines. Environ. Pollut. 159, 3653-3659.

Kim, J.W., Isobe, T., Sudaryanto, A., Malarvannan, G., Chang, K.H., Muto, M. Prudente, M. Tanabe, S., 2013. Organophosphorus flame retardants in house dust from the Philippines: occurrence and assessment of human exposure. Environ. Sci. Pollut. Res. 20, 812-822.
Kim, J.W., Isobe, T., Muto, M., Tue, N.M., Katsura, K., Malarvannan, G., Sudaryanto, A., Chang, K.H., Prudente, M., Viet, P.H., Takahashi, S., Tanabe, S., 2014 Dec. Organophosphorus flame retardants (PFRs) in human breast milk from several Asian countries. Chemosphere 116, 91-97. http://dx.doi.org/10.1016/j.chemosphere.2014.02.033. Epub 2014 Mar 13.

Luongo, G., Ostman, C., 2016. Organophosphate and phthalate esters in settled dust from apartment buildings in Stockholm. Indoor Air 2016 (26), 414-425.

Ma, Y.Q., Cui, K.Y., Zeng, F., Wen, J.X., Liu, H., Zhu, F., Ouyang, G.F., Luan, T.G., Zeng, Z.X., 2013. Microwave-assisted extraction combined with gel permeation chromatography and silica gel cleanup followed by gas chromatography-mass spectrometry for the determination of organophosphorus flame retardants and plasticizers in biological samples. Anal. Chim. Acta 786, 47-53.

Makinen, M.S.E., M€akinen, M.R.A., Koistinen, J.T.B., Pasanen, A.-L., Pasanen, P.O. Kalliokoski, P.I., Korpi, A.M., 2009. Respiratory and dermal exposure to organophosphorus flame retardants and tetrabromobisphenol A at five work environments. Environ. Sci. Technol. 43, 941-947.

Malarvannan, G., Belpaire, C., Geeraerts, C., Eulaers, I., Neels, H., Covaci, A., 2015. Organophosphorus flame retardants in the European eel in Flanders, Belgium: occurrence, fate and human health risk. Environ. Res. 140, 604-610.

Marklund, A., Andersson, B., Haglund, P., 2003. Screening of organophosphorus compounds and their distribution in various indoor environments. Chemosphere 53, 1137-1146.

Marklund, A., Olofsson, U., Haglund, P., 2010. Organophosphorus flame retardants and plasticizers in marine and freshwater biota and human milk. J. Environ. Monit. 12, 943-951.

Martínez-Carballo, E., Gonzalez-Barreiro, C., Sitka, A., Scharf, S., Gans, O., 2007. Determination of selected organophosphate esters in the aquatic environment of Austria. Sci. Total Environ. 388, 290-299.

Meeker, J.D., Cooper, E.M., Stapleton, H.M., Hauser, R., 2013. Urinary metabolites of organophosphate flame retardants: temporal variability and correlations with house dust concentrations. Environ. Health Perspect. 121, 580-585.

Meyer, J., Bester, K., 2004. Organophosphate flame retardants and plasticisers in wastewater treatment plants. J. Environ. Monit. 6, 599-605.

NFA, 2012. Market Basket 2010 - Chemical Analysis, Exposure Estimation and Health-related Assessment of Nutrients and Toxic Compounds in Swedish Food Baskets. The National Food Agency, Uppsala, Sweden (Report no. 7-2012).

Rodil, R., Benito Quintana, J., Concha-Grana, E., Lopez-Mahía, P., MuniateguiLorenzo, S., Prada-Rodríguez, D., 2012. Emerging pollutants in sewage, surface and drinking water in Galicia (NW Spain). Chemosphere 86, 1040-1049.

Stapleton, H.M., Klosterhaus, S., Eagle, S., Fuh, J., Meeker, J.D., Blum, A., Webster, T.F., 2009. Detection of organophosphate flame retardants in furniture foam and US house dust. Environ. Sci. Technol. 43, 7490-7495.

Su, G., Crump, D., Letcher, R.J., Kennedy, S.W., 2014. Rapid in vitro metabolism of the flame retardant triphenyl phosphate and effects on cytotoxicity and mRNA expression in chicken embryonic hepatocytes. Environ. Sci. Technol. 48, 13511-13519.

Sundkvist, A.M., Olofssona, U., Haglunda, P., 2010. Organophosphorus flame retardants and plasticizers in marine and fresh water biota and in human milk. J. Environ. Monit. 12, 943-951.

Swedish board of agriculture. SBA, 2013. Archive on Food Consumption: Food Consumption and Nutritive Values, Data up to 2013. https://www. jordbruksverket.se/webdav/files/SJV/Amnesomraden/Statistik,\%20fakta/ Livsmedel/JO44SM1401/JO44SM1401_inEnglish.htm.

Van de Eede, N., Dirtu, A., Neels, H., Covaci, A., 2011. Analytical developments and preliminary assessment of human exposure to organophosphate flame retardants from indoor dust. Environ. Int. 37, 454-461.

Van der Veen, I., De Boer, J., 2012. Phosphorus flame retardants: properties, production, environmental occurrence, toxicity and analysis. Chemosphere 88, 1119-1153.

Wang, X.W., He, Y.Q., Lin, L., Zeng, F., Luan, T.G., 2014. Application of fully automatic hollow fiber liquid phase microextraction to assess the distribution of organophosphate esters in the Pearl River Estuaries. Sci. Total Environ. 470-471, 263-269.

Wei, G.L., Li, D.Q., Zhuo, M.N., Liao, Y.S., Xie, Z.Y., Guo, T.L., Li, J.J., Zhang, S.Y., Liang, Z.Q., 2015. Organophosphorus flame retardants and plasticizers: sources, occurrence, toxicity and human exposure. Environ. Pollut. 196, 29-46.

World Health Organization, 1998. Environmental Health Criteria 209, Flame ReTardants: Tris(chloropropyl) Phosphate and Tris(2-chloroethyl) Phosphate. World Health Organization, Geneva, Switzerland.

World Health Organization, 2000. Environmental Health Criteria 218, Flame Retardants: Tris(2-butoxyethyl) Phosphate, Tris(2-ethylhexyl) Phosphate and Tetrakis(hydroxymethyl) Phosphonium Salts. World Health Organization, Geneva.

Xu, F., García-Bermejo, A., Malarvannan, G., Gomara, B., Neels, H., Covaci, A., 2015. Multi-contaminant analysis of organophosphate and halogenated flame retardants in food matrices using ultrasonication and vacuum- assisted extraction, multi-stage cleanup and gas chromatography-mass spectrometry. J. Chromatogr. A 1401, 33-41.

Yang, F.X., Ding, J.J., Huang, W., Xie, W., Liu, W.P., 2014. Particle size-specific distributions and preliminary exposure assessments of organophosphate flame retardants in office air particulate matter. Environ. Sci. Technol. 48, 63-70.

Zeng, X.Y., He, L.X., Cao, S.X., Ma, S.T., Yu, Z.Q., Gui, H.Y., Sheng, G.Y., Fu, J.M., 2014. Occurrence and distribution of organophosphate flame retardants/plasticizers in wastewater treatment plant sludges from the Pearl River Delta, China. Environ. Toxicol. Chem. 33, 1720-1725. 